\title{
Synthetic grafts in the treatment of ruptured anterior cruciate ligament of the knee joint
}

\author{
Wojciech Satora ${ }^{1, A-F}$, Aleksandra Królikowska ${ }^{2, A, E, F}$, Andrzej Czamara ${ }^{2, A, E, F}$, Paweł Reichert ${ }^{3, A, E, F}$ \\ 1 Department of Trauma and Orthopedic Surgery, St. Luke's Hospital, Bielsko-Biała, Poland \\ 2 College of Physiotherapy in Wrocław, Wrocław, Poland \\ ${ }^{3}$ Division of Sports Medicine, Wroclaw Medical University, Wrocław, Poland \\ A - research concept and design; B - collection and/or assembly of data; $\mathrm{C}$ - data analysis and interpretation; \\ $D$ - writing the article; $E$ - critical revision of the article; $F$ - final approval of article
}

\section{Address for correspondence}

Paweł Reichert

E-mail: pawelreichert74@gmail.com

Funding sources

none declared

Conflict of interest

none declared

Received on August 18, 2017

Revised on September 03,2017

Accepted on September 09, 2017

\begin{abstract}
The anterior cruciate ligament (ACL) is cited as the most frequently injured ligament in the knee. The standard treatment of ACL injury remains ligament reconstruction followed by a postoperative physiotherapeutic procedure. During the reconstruction, the torn ligament can be replaced with an autograft or an allograft. A synthetic ligament is also one of the available graft options. Synthetic grafts in ruptured ACL treatment have been used as scaffolds, stents, or prostheses. The story of using synthetic materials in ACL deficient knee treatment started in the beginning of the $20^{\text {th }}$ century with the usage of silk and silver fibers. The second half of the $20^{\text {th }}$ century abounded in new synthetic materials being proposed as torn ACL replacements, such as Supramid ${ }^{\circledR}$, Teflon ${ }^{\circledR}$ or Dacron ${ }^{\circledR}$, Proplas ${ }^{\circledR}$, carbon fiber graft, ABC graft, Kennedy-LAD ${ }^{\circledR}$, Trevia, Leeds-Keio, Gore-Tex ${ }^{\circledR}$, PDS $^{\circledR}$, EULIT ${ }^{\circledR}$, and Polyflex ${ }^{\circledR}$ or LARS ${ }^{\circledR}$. Artificial ligaments have intrigued surgeons for all these years as they represent the hope for grafts that are easily available and stronger than soft tissue "off-the-shelf" grafts, simplifying the surgery, and avoiding graft harvesting and donor site morbidity. However, most of the artificial grafts have been characterized by high rates of failure. One of the very few synthetic grafts gaining more widespread popularity has been $\operatorname{LARS}{ }^{\circledR}$. However, it is suggested that the ligament not be considered as a potential graft for primary reconstruction of the $\mathrm{ACL}$, and it should be rather treated as an alternative graft in special cases, so the optimal synthetic graft material remains controversial.
\end{abstract}

Key words: artificial ligament, ligament prostheses, ligament reconstruction
DOI

10.17219/pim/76819

Copyright

○ 2017 by Wroclaw Medical University

This is an article distributed under the terms of the Creative Commons Attribution Non-Commercial License (http://creativecommons.org/licenses/by-nc-nd/4.0/) 
The anterior cruciate ligament (ACL) is cited as the most frequently injured ligament in the human knee. ${ }^{1,2}$ In the USA, the average incidence frequency of ACL injuries amounts to 200,000 cases per year. ${ }^{3}$ The injuries most commonly occur in physically active individuals while playing multidirectional sports. ${ }^{1}$ For patients wishing to return to sports activities, the standard treatment for ACL injury is the reconstruction of the ligament, ${ }^{4}$ followed by a postoperative physiotherapeutic procedure. ${ }^{5}$ The aim of the reconstruction is reinstating functional knee stability, and in turn, reducing the risk of secondary injuries, such as further damage to the menisci and degenerative osteoarthritis. ${ }^{6,7}$ A recent analysis of epidemiological data shows an increase of the incidence of ACL ruptures and subsequent reconstructions. ${ }^{8}$

\section{Anterior cruciate ligament ( $A C L)$ of the knee joint}

The ACL is one of the intra-articular ligaments of the knee joint. The ACL and the posterior cruciate ligament (PCL) are the most important stabilizers in the sagittal plane of the knee as they aim to stabilize the joint against the large anterior-posterior shear forces occurring while walking or running. "Cruciate", literally meaning "cross", and describes the shape of the ACL and PCL as they interconnect the tibia with the femur.

The ACL attaches to a facet on the anterior part of the intercondylar area of the tibia and ascends posteriorly where it is attached to a facet at the back of the lateral wall of the intercondylar fossa of the femur. Functionally, the ACL consists of 2 distinct bundles that are characterized by a spatial relationship throughout the knee flexion: the anteromedial (AM) and posterolateral (PL) bundles. The bundles also play different roles in the biomechanics and stability of the joint. ${ }^{9-11}$ Some authors have distinguished a $3^{\text {rd }}$ bundle in the anatomy of the ACL, the intermediate (IM) bundle. ${ }^{12,13}$

The ACL aims to resist anterior displacement and excessive rotation of the tibia relative to the femur. ${ }^{11}$

\section{ACL injury and its treatment}

The ACL injury mechanism involves a combination of large rotational, side-to-side, and hyperextension forces through the knee.

During the reconstruction, the torn ligament can be replaced with an autograft or an allograft. Synthetic ligament usage is also one of the available graft options. Autograft choices involve the patellar, hamstring, and quadriceps tendons, while the allograft options consist of the quadriceps, patellar, Achilles, hamstring, and anterior and posterior tibialis tendons, and the fascia lata. ${ }^{14}$
Shorter surgical and anesthesia time, fewer postoperative complications, reduced morbidity at the harvest site, faster postoperative recovery and lower incidence of postoperative arthrofibrosis, and less postoperative pain are considered to be the main advantages of allograft usage for ACL replacement. ${ }^{15,16}$ On the other hand, allograft usage may be associated with higher rates of re-rupture, limited availability, a delayed healing and ligamentization process in comparison to autografts, risk of disease transmission and expensiveness. ${ }^{17-19}$ The synthetic materials being used in ACL reconstruction were introduced with an aim to improve the strength and stability of the graft immediately after the reconstruction, reduce donor site morbidity and eliminate the potential for disease transmission. ${ }^{20}$ However, the first artificial grafts were characterized by high rates of failure and synovitis reactivation, ${ }^{21,22}$ thus with advancing technology, new synthetic materials have been developed for ACL reconstruction grafts. ${ }^{23}$ The optimal graft material remains controversial.

\section{Artificial ligament usage in ACL reconstruction}

Synthetic grafts in ruptured ACL treatment have been used as scaffolds, stents, or prostheses. ${ }^{14}$

A scaffold, such as the carbon fiber scaffold ligament, was introduced with the purpose of stimulating fibrous tissue ingrowth, and contributes to the ultimate strength of the new ligament. ${ }^{24}$ An example of a synthetic stent is the Kennedy ligament augmentation device (LAD). ${ }^{24}$ An example of a prosthetic graft was the Gore-Tex graft, Stryker Dacron graft, or ABC graft.

\section{The first half of the $20^{\text {th }}$ century}

The history of the use of synthetic materials to replace the ACL goes back to the year 1903, when prosthetic ligaments made of silk sutures were introduced by Fritz Lange of Munich. ${ }^{25}$ Four years later, Lange reported on 4 cases of patients with ACL deficiency whose knees were stabilized with the use of artificial ligaments made of silk in conjunction with the semitendinosus and semimembranosus muscle tendons placed extra-articularly. ${ }^{26}$ However, in 1918, Smith of Cardiff criticized the silk fibers, considering them to be the cause of synovitis in his patient, ${ }^{21}$ sharing the same opinion with Max Herz (1906), ${ }^{22}$ and confirming the failure of silk usage in isolation within the intra-articular environment. The answer to that was introducing a foreign body scaffold aiming to provide initial strength during ligament healing and re-growth, and utilizing in ACL reconstruction silk augmented with fascia by Max Fritz of Munich, ${ }^{27}$ followed by Karl Ludloff of Frankfurt in 1927. ${ }^{28}$

Another example of a synthetic material being used for ACL replacement was a loop of silver wire introduced by Edred Corner of London in 1914. ${ }^{29}$ 


\section{The second half of the $20^{\text {th }}$ century}

In 1949, Ruther of Germany introduced a synthetic ligament for ACL replacement made of a polyamide derivative, and named Supramid. ${ }^{30}$ Nevertheless, the results of treatment with the use of Supramid were disappointing. ${ }^{30}$

After a successful implantation of Teflon grafts into dog knees, ${ }^{31}$ Olav Rostrup of Edmonton in 1959 started using the synthetic material in humans. ${ }^{32} \mathrm{He}$ didn't recommend Teflon or Dacron for wide-scale use as he considered synthetic materials to be rather supporting devices, instead of ligament replacements. Even so, the ligament replacement device named Dacron was made commercially available in the 1980s by Stryker, but production was finally discontinued in 1994 as the results of treatment with its use were not satisfying. An evaluation carried out by Wilk and Richmond (1993) of patients after ACL reconstruction with the use of Dacron revealed significant deterioration of the ligament failure rate from $20 \% 2$ years postoperatively up to $37.5 \%$ at 5 years. ${ }^{33}$ The high rate of graft failure was confirmed by Maletius and Gillquist (1997) in a 9-year follow-up, amounting $44 \% .^{34}$

Another synthetic graft being used in the second half of the $20^{\text {th }}$ century was a porous Teflon graft, named Proplast. Interestingly, it was one of the first synthetic graft materials approved by the Food and Drug Administration (FDA), however, the results of its clinical usage were not satisfying. ${ }^{35}$

Also, flexible carbon fiber was introduced as a synthetic graft material for ACL reconstruction. ${ }^{36}$ David Jenkins of Cardiff started to use them in the mid-1980s as a scaffold aiming to encourage the ingrowth of fibroblastic tissue and production of new collagen. Nevertheless, the occurrence of the fragmentation of carbon creating unsightly staining of the synovium and foreign body reaction was noted. In 1985, Angus Strover of South Africa didn't notice any occurrence of carbon debris in the knee joint cavity when the carbon fibers were used with the remnants of the original ligament or within a fascia sheath. ${ }^{37}$

When it comes to Poland, the wide-ranging studies concerning carbon fiber usage generally in knee surgery and knee ligament reconstructions, especially in ACL reconstruction, have been carried out mainly by Andrzej Górecki and Wojciech Kuś in the Clinics of Orthopedics and Traumatology of the Medical University in Warszawa in cooperation with the AGH University of Science and Technology in Kraków. ${ }^{38,39}$

The mid-1980s also brought the ligament replacement named Activated Biological Composite $(A B C)$. The ABC graft, being a combination of polyester and carbon fiber, was placed through anatomical bony tunnels. In the beginning, the ligament gained popularity, however, eventually became obsolete like other synthetic grafts. ${ }^{23}$

An example of an ACL augmentation device was the Kennedy-LAD, made of polypropylene and introduced by Jack Kennedy of London in the late 1970 s. ${ }^{40}$ The synthetic stent was sutured to an autologous graft and fixed to the bone at both ends, with the aim to support and protect the autologous graft during the healing phase, when the autologous tissue was the weakest. The LAD was a bandlike braid of propylene that was designed to protect the autogenous graft from excessive stresses, however it happened to stress the autologous graft, leading to failure. ${ }^{41}$ One polyester graft resembling LAD in design, but being placed in a nonanatomic position was Trevia. The LeedsKeio was a polyester mesh graft designed in order to augment the autogenous graft that was placed through bony tunnels and fixed outside the tunnel with staples. A Murray et al. study reporting the long-term results of patients 10-16 years after ACL reconstruction with the use of the Leeds-Keio ligament revealed rather poor results with a high rate of ligament rupture and knee laxity. ${ }^{42}$ Also, LAD usage results indicted a high rate of postoperative complications and re-surgeries, ${ }^{43}$ as well as causing effusions and synovitis reactivation and autogenous graft delay. ${ }^{44}$ All in all, it was suggested not to use Leeds-Keio or LAD devices due to their poor outcomes. ${ }^{45}$

Other examples of synthetic grafts were Gore-Tex, PDS, EULIT, and Polyflex. ${ }^{23,46}$ The Gore-Tex graft was a prosthetic graft that, theoretically, aiming to avoid the bending forces at the entrance to the femoral tunnel, was placed in a nonanatomic position over the top of the femur.

\section{Ligament advanced reinforcement system (LARS)}

One of the synthetic material grafts introduced in the second half of the $20^{\text {th }}$ century was a graft made of polyester named Ligostic, which evolved to a non-absorbable synthetic ligament device made of terephthalic polyethylene polyester fibers, the Ligament Advanced Reinforcement System (LARS). ${ }^{47}$ The LARS is intensively cleaned with the aim to remove potential machining residues and oils to further encourage soft tissue in-growth and reduce the risk of reactive synovitis. The LARS consists of 2 parts, an intraarticular part and an extraarticular one. The ligament intra-articular portion/scaffold is built of multiple parallel fibers that are twisted at 90-degree angles. ${ }^{47}$ The part is composed of 2 longitudinal external rotation fibers without transverse fibers, being designed as an imitation of ACL anatomic structure. The extraarticular part is waved by longitudinal and transverse fibers with the aim to avoid ligament deformation. The short-term postoperative results of patients after ACL reconstruction with the use of LARS are very satisfying. ${ }^{48}$ A mean 2.5-year follow up carried out by Dericks in 1995 revealed encouraging results of treatment with the use of LARS. ${ }^{47}$ Also, a follow-up at a mean of 8 years reported by Parchi et al. in 2013 showed satisfying results reflected in no postoperative complication occurrence and only one case of LARS rupture. ${ }^{49}$ On the other hand, the follow-up of 10 years postoperatively carried out by Tiefenboeck et al. (2015) 
revealed lack of subjective satisfaction in half of patients treated with the use of LARS, thus the authors suggested not to consider the ligament system as a potential graft for primary reconstruction of the ACL and rather treat it as an alternative graft in special cases. ${ }^{50}$

\section{Summary}

The story of using synthetic materials in ACL deficient knee treatment started in the beginning of $20^{\text {th }}$ century with the usage of silk and silver fibers. The story of using synthetic materials in ACL deficient knee treatment started in the beginning of the $20^{\text {th }}$ century with the usage of silk and silver fibers. The second half of the $20^{\text {th }}$ century abounded in new synthetic materials being proposed as torn ACL replacements such as Supramid, Teflon or Dacron, Proplast, carbon fiber graft, ABC graft, Kennedy-LAD, Trevia, Leeds-Keio, Gore-Tex, PDS, EULIT, and Polyflex or LARS.

Artificial ligaments have intrigued surgeons for all these years as they represent the hope for grafts that are easily available and stronger than soft tissue "off-the-shelf" grafts, simplifying the surgery, and avoiding graft harvesting and donor site morbidity. However, most of the artificial grafts have been characterized by high rates of failures. One of the very few synthetic grafts gaining more widespread popularity and which remains in use as an augmentation device up to this day has been LARS. However, it is suggested that the ligament should not be considered as a potential graft for primary reconstruction of the ACL, but should be rather treated as an alternative graft in special cases, so the optimal synthetic graft material remains controversial.

\section{References}

1. Gianotti SM, et al. Incidence of anterior cruciate ligament injury and other knee ligament injuries: A national population-based study. J Sci Med Sport. 2009;12(6):622-627.

2. Janssen KW, et al. High incidence and costs for anterior cruciate ligament reconstructions performed in Australia from 2003-2004 to 2007-2008: Time for an anterior cruciate ligament register by Scandinavian model? Scand J Med Sci Sports. 2012;22(4):495-501.

3. Prodromos CC, et al. A meta-analysis of the incidence of anterior cruciate ligament tears as a function of gender, sport, and a knee injury-reduction regimen. Arthroscopy. 2007;23(12):1320-1325.

4. Ekstrand J. A 94\% return to elite level football after ACL surgery: A proof of possibilities with optimal caretaking or a sign of knee abuse? Knee Surg, Sports Traumatol, Arthrosc. 2011;19(1):1-2.

5. Arna Risberg M, Lewek M, Snyder-Mackler L. A systematic review of evidence for anterior cruciate ligament rehabilitation: how much and what type? Phys Ther Sport. 2004;5(3):125-145.

6. George MS, Dunn WR, Spindler KP. Current concepts review: Revision anterior cruciate ligament reconstruction. Am J Sports Med. 2006;34(12):2026-2037.

7. Chaudhari AM, et al. Knee kinematics, cartilage morphology, and osteoarthritis after ACL injury. Med Sci Sports Exerc. 2008;40(2):215-222.

8. Buller LT, et al. Trends in anterior cruciate ligament reconstruction in the United States. Orthop J Sports Med. 2015;3(1):2325967114563664.

9. Palmer I. On the injuries to the ligaments of the knee joint: A clinical study. Acta Chir Scand. 1938;91:282.
10. Abbott LC, et al. Injuries to the ligaments of the knee joint. J Bone Joint Surg. 1944;26(3):18.

11. Girgis FG, Marshall JL, Monajem A. The cruciate ligaments of the knee joint. Anatomical, functional and experimental analysis. Clin Orthop Relat Res. 1975(106):216-231.

12. Norwood LA, Cross MJ. Anterior cruciate ligament: Functional anatomy of its bundles in rotatory instabilities. Am J Sports Med. $1979 ; 7(1): 23-26$.

13. Amis AA, Dawkins GP. Functional anatomy of the anterior cruciate ligament. Fibre bundle actions related to ligament replacements and injuries. J Bone Joint Surg Br. 1991;73(2):260-267.

14. West RV, Harner CD. Graft selection in anterior cruciate ligament reconstruction. J Am Acad Orthop Surg. 2005;13(3):197-207.

15. Cohen SB, Sekiya JK. Allograft safety in anterior cruciate ligament reconstruction. Clin Sports Med. 2007;26(4):597-605.

16. Zeng $C$, et al. Autograft versus allograft in anterior cruciate ligament reconstruction: A meta-analysis of randomized controlled trials and systematic review of overlapping systematic reviews. Arthroscopy. 2016;32(1):153-163.

17. Samuelsson $\mathrm{K}$, et al. Trends in surgeon preferences on anterior cruciate ligament reconstructive techniques. Clin Sports Med. 2013;32(1):111-126.

18. Barrera Oro F, et al. Autograft versus allograft: An economic cost comparison of anterior cruciate ligament reconstruction. Arthroscopy. 2011;27(9):1219-1225.

19. Cooper MT, Kaeding C. Comparison of the hospital cost of autograft versus allograft soft-tissue anterior cruciate ligament reconstructions. Arthroscopy. 2010;26(11):1478-1482.

20. Johnson D. Why synthetic grafts failed, in the anterior cruciate ligament: Reconstruction and basic science. C. Prodromos, C., Editor. 2008, Saunders Elsevier: Philadelphia, 88-90.

21. Smith A. The diagnosis and treatment of injuries to the crucial ligaments. Br J Surg. 1918;6:176-189.

22. Herz M. Die chirurgische Behandlung paralytischer Schlotterelenke-Seitenligamente oder Arthrodese? [The surgical treatment of paralytic flail knees: Silk ligaments or arthrodesis]. Munch Med Wschr. 1906;51:2527-2529.

23. Schindler OS. Surgery for anterior cruciate ligament deficiency: A historical perspective. Knee Surg Sports Traumatol Arthrosc. 2012;20(1):5-47.

24. Zoltan DJ, Reinecke C, Indelicato PA. Synthetic and allograft anterior cruciate ligament reconstruction. Clin Sports Med. 1988;7(4):773-784.

25. Lange F. Uber the Sehnenplastik [On the tendon reconstruction]. Verh Dtsch Orthop Ges. 1903;2:10-12.

26. Lange F. Kunstliche Gelenkbander aus Seide [On artificial silk ligaments]. Munch Med Wschr. 1907;52:834-836.

27. Lange M. Unfallorthopadie. 1949, Stuttgart: Ferdinand Enke.

28. Ludloff K. Der operative Ersatz des vorderen Kreuzbandes am Knie [Surgical replacement of the anterior cruciate ligament]. Zentralbl Chir. 1927;54:3162-3166.

29. Corner EM. The exploration of the knee-joint: With some illustrative cases. Br J Surg. 1914;2(6):191-204.

30. Ruther H. Die Verwendung von Supramid in der operativen Orthopadie. Z Orthop. 1949;78:161-169.

31. Emery MA, Rostrup O. Repair of the anterior cruciate ligament with $8 \mathrm{~mm}$, tube teflon in dogs. Can J Surg. 1960;4:111-115.

32. Rostrup $O$. Reconstruction of the anterior cruciate ligaments. West J Surg Obstet Gynecol. 1964;72:199-202.

33. Wilk RM, Richmond JC. Dacron ligament reconstruction for chronic anterior cruciate ligament insufficiency. Am J Sports Med. 1993;21(3):374-379.

34. Maletius W, Gillquist J. Long-term results of anterior cruciate ligament reconstruction with a Dacron prosthesis. The frequency of osteoarthritis after seven to eleven years. Am J Sports Med. 1997;25(3):288-293.

35. Woods GW, et al. Proplast leader for use in cruciate ligament reconstruction. Am J Sports Med. 1979;7(6):314-320.

36. Jenkins $\mathrm{DH}$. The repair of cruciate ligaments with flexible carbon fibre. A longer term study of the induction of new ligaments and of the fate of the implanted carbon. J Bone Joint Surg Br. 1978;60-b(4):520-522.

37. Strover $A E$, Firer $P$. The use of carbon fiber implants in anterior cruciate ligament surgery. Clin Orthop Relat Res. 1985(196):88-98.

38. Górecki A. Przydatność włókien węglowych w śródstawowych rekon- 
strukcjach przedniego więzadła krzyżowego stawu kolanowego. 1983, Rozprawa doktorska, Akademia Medyczna w Warszawie.

39. Kuś W. Badania doświadczalne nad zastosowaniem włókien węglowych w operacjach odtwórczych narządu ruchu. 1986, Rozprawa habilitacyjna, Akademia Medyczna w Warszawie.

40. Kennedy J, Willis R. Synthetic cruciate ligaments: Preliminary report. J Bone Jt Surg. 1976;58(B):142.

41. Drogset JO, et al. A sixteen-year follow-up of three operative techniques for the treatment of acute ruptures of the anterior cruciate ligament. J Bone Joint Surg Am. 2006;88(5):944-952.

42. Murray AW, Macnicol MF. 10-16 year results of Leeds-Keio anterior cruciate ligament reconstruction. The Knee. 2004;11(1):9-14.

43. Riel KA. Augmented anterior cruciate ligament replacement with the Kennedy-LAD (ligament augmentation device) - long term outcome. Zentralb/ Chir. 1998;123(9):1014-1018.

44. Kumar K, Maffulli N. The ligament augmentation device: A historical perspective. Arthroscopy. 1999;15(4):422-432.

45. Jia ZY, et al. Comparison of artificial graft versus autograft in anterior cruciate ligament reconstruction: A meta-analysis. BMC MusCuloskelet Disord. 2017;18(1):309.

46. James $\mathrm{SL}$, et al. Cruciate ligament stents in reconstruction of the unstable knee. A preliminary report. Clin Orthop Relat Res. 1979(143):90-96.

47. Dericks G. Ligament advanced reinforcement system anterior cruciate ligament reconstruction. Operative Techniques in Sports Medicine. 1995;3(3):187-205.

48. Krupa S, Krolikowska A, Reichert P. Postoperative knee joint stability following anterior cruciate ligament reconstruction using the ligament advanced reinforcement system. Polim Med. 2016;46(2):155-161.

49. Parchi PD, et al. Anterior cruciate ligament reconstruction with LARS artificial ligament results at a mean follow-up of eight years. Int Orthop. 2013;37(8):1567-1574.

50. Tiefenboeck TM, et al. Clinical and functional outcome after anterior cruciate ligament reconstruction using the LARS system at a minimum follow-up of 10 years. Knee. 2015;22(6):565-568. 